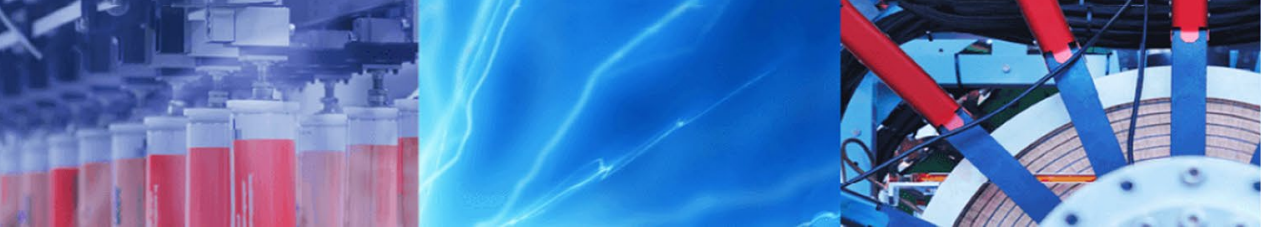

Research Article

\title{
Photo catalytic degradation of methylene blue and methyl orange from aqueous solution using solar light onto chitosan bi-metal oxide composite
}

\author{
M. Makeswari ${ }^{1}$ (D) P. Saraswathi ${ }^{2}$
}

Received: 23 September 2019 / Accepted: 6 January 2020 / Published online: 4 February 2020

(c) Springer Nature Switzerland AG 2020

\begin{abstract}
Chitosan bi-metal oxide (CBMO) is prepared by co-precipitation method to determine the degradation ability of methylene blue (MB) and methyl orange (MO) dyes using solar light irradiation. The characteristics of CBMO are studied by FTIR, UV, SEM, EDX and XRD studies. The photocatalytic degradation of studies MB and MO were carried out by varying the parameters such as $\mathrm{pH}$, irradiation time, dye concentration, composite dosage. The photo catalytic study shows the maximum percentage of degradation at $\mathrm{pH} 8$ for $\mathrm{MB}$ and 3 for $\mathrm{MO}$ at irradiation time of $120 \mathrm{~min}$ and $0.15 \mathrm{~g}$ of $\mathrm{CBMO}$ and is confirmed by UV spectral studies. Based on the equilibrium data value Langmuir isotherm is well fitted, which indicates the formation of strong monolayer and it obeys pseudo second order kinetic model. Among methylene blue and methyl orange dyes, methyl orange was highly degraded (74.05\%) by the chitosan-bimetal oxide adsorbent. And also $62.05 \%$ of dyes can be removed from industrial waste water by CBMO. According to the experimental results it is clearly evident that the chitosan-bimetal oxide composite is expected to be an effective product for the remediation of dyes from waste water.
\end{abstract}

Keywords Chitosan bi-metal oxide · Degradation · Methylene blue · Methyl orange · Solar light · Langmuir isotherm · Second order kinetic model

\section{Introduction}

In the present scenario dyes, pigments and colour products play a vital role in various activities like food production, cosmetics, pharmaceuticals, leather, beverage and also in paper industries [1]. It contains complex structure, non-biodegradability and harmfulness towards animals, plants and environment. Around 700,000 varieties of dyes are produced per year in the worldwide market, in which most of the dyes are discharged from textile industries and contaminated the water resources $[2,3]$. MB and MO are most commonly used cationic and anionic dyes in dyeing, printing, cosmetics and leather industries [4]. Releases of these dyes into aquatic steams restrict the penetration of sunlight that leads to destroy the life of aquatic organisms. It causes several health hazards to human beings like vomiting, breathing problem, diarrhoea and skin irritation [5]. Now a day's degradation and removal of these dyes before discharging into the water bodies is the challenging task. Several methods are available to treat dye effluents such as coagulation, electro precipitation, reverse osmosis, adsorption, evaporation, flocculation, advanced oxidation process and photo catalytic degradation by using UV and solar light irradiation [6, 7]. Among all these methods degradation by solar light irradiation is the effective and easy method to remove dyes from dye effluent, because the solar energy is naturally available and does not produce sludge during degradation and quietly low

M. Makeswari, makeswari.chem22@gmail.com | ${ }^{1}$ Department of Chemistry, Karpagam Academy of Higher Education, Coimbatore, Tamil Nadu 641021, India. ${ }^{2}$ Department of Chemistry, SNS College of Engineering, Coimbatore, Tamil Nadu 641107, India. 
cost when compared to other methods $[8,9]$. According to previous literature number of attempts is made by many researchers for the degradation of $M B$ and $M O$ dye by photo catalytic degradation (UV/Solar irradiation) using various materials such as $\mathrm{Cu}_{2} \mathrm{O} / \mathrm{LDH}$ [10], Chitosan Zinc Oxide hybrid composite [11], $\mathrm{BiFeO}_{3}$ [12], ZnO [13], $\mathrm{CuCl}_{2}+\mathrm{STS}$, Chitosan-g-Poly (acrylamide)/ZnS [14], Chitosan/ $\mathrm{LaFe}_{0.8} \mathrm{Cu}_{0.2} \mathrm{O}_{3}$ and Xylan/LaFe ${ }_{0.8} \mathrm{Cu}_{0.2} \mathrm{O}_{3}[15]$.

Chitosan is the second abundant natural polysaccharide derivative obtained from the deacetylation of chitin next to cellulose which has the capacity to degrade organic pollutants due to its numerous amide groups in its inter linked structure [16]. Modification of Chitosan by grafting process increases the degradation ability with its superior properties. Due to its inter and intra molecular hydrogen bonding between $\mathrm{H}^{+}$and $-\mathrm{NH}_{2}$, Chitosan dissolves only in acid medium [17]. Modified Chitosan composites are more suitable for anionic dyes than cationic dyes.

Generally the metal oxides possess good degradation ability towards organic pollutants due to its extensive properties like high surface area, low production and regeneration cost [18] and it is superior to other traditional adsorbents due to the absence of internal diffusion resistance. Based on previous literature studies many researchers involved in the preparation of bi-metal oxides in wastewater treatment, the reason is that it produces high degradation efficiency than mono metallic oxides; monometallic oxides are deactivated easily by $\mathrm{pH}$ alterations and it produces low degradation efficiency [19-22].

The objective of this present work is to prepare the modified chitosan by $\mathrm{Zn}-\mathrm{Mg}$ bimetal oxide using grafting process (insertion of functional groups) and to examine the degradation ability towards $\mathrm{MB}$ and $\mathrm{MO}$ and to investigate the degradation ability of CBMO onto industrial waste water. Optimization of photocatalytic degradation parameters and characterisation of CBMO composites were examined.

\section{Experimental}

\subsection{Materials}

$M B$ is a classical cationic dye with molecular formula $\mathrm{C}_{16} \mathrm{H}_{18} \mathrm{~N}_{3} \mathrm{ClS}$, and $\lambda_{\max } 663 \mathrm{~nm}$ and $\mathrm{MO}$ dye is a typical anionic dye with molecular formula $\mathrm{C}_{14} \mathrm{H}_{14} \mathrm{~N}_{3} \mathrm{NaO}_{3} \mathrm{~S}$ with $\lambda_{\max }$ $464 \mathrm{~nm}$; it is used as adsorbate to identify the degradation ability of CBMO. Analytical grade chemicals and reagents of Zinc Sulphate, Magnesium Sulphate, Chitosan, Acetic acid, $\mathrm{HCl}, \mathrm{NaOH}$ are procured from Universal Scientific Company, Coimbatore, India. The entire study was carried out by using double distilled water. A stock solution of $1000 \mathrm{mg} / \mathrm{L}$ of MB and MO was prepared by dissolving $1 \mathrm{~g}$ of dye in the double distilled water. Industrial wastewater is collected from Mangalam, Tirupur district.

\subsection{Preparation of CBMO}

Double distilled water is used to prepare equimolar solutions of Zinc Sulphate and Magnesium Sulphate and the solutions are mixed well and the mixture is stirred in magnetic stirrer for $3 \mathrm{~h}$ to obtain $\mathrm{Zn}-\mathrm{Mg}$ Bimetal Oxide. The resultant product is washed well with double distilled water to reach neutral $\mathrm{pH}$. The prepared product is filtered and dried at room temperature. The $\mathrm{Zn}-\mathrm{Mg}$ Bimetal Oxide and the chitosan in 5\% acetic acid solution is mixed thoroughly and the whole content is agitated in a magnetic stirrer for $2 \mathrm{~h}$ at room temperature [23]. After agitation the product is filtered, dried and calcinated in a hot air oven. The calcinated CBMO is crushed and packed in an air tight container for further studies.

\subsection{Characterization of CBMO}

The physiochemical characteristics such as moisture content, yield, $\mathrm{pH}$, composite surface acidity and basicity, iodine number and the presence of carboxyl, carboxylic and phenolic groups are studied and reported. The surface characteristics such as SEM, EDX, XRD and FTIR also studied and reported for the prepared CBMO.

\subsection{Photo catalytic studies}

The photocatalytic degradation efficiency of CBMO is studied by varying irradiation time, $\mathrm{pH}, \mathrm{CBMO}$ dose and initial dye concentration of $\mathrm{MB}$ and $\mathrm{MO}$ using batch mode experiments. It is carried out by using $250 \mathrm{ml}$ borosil conical flasks. $50 \mathrm{ml}$ of dye is taken in a series of $250 \mathrm{ml}$ conical flasks with various dye concentration and known amount of CBMO is stirred well. The stirred mixture is agitated in a bench shaker for 10-15 min for the attainment of equilibrium between composite and adsorbate solution. $0.1 \mathrm{~N}$ $\mathrm{HCl}$ and $0.1 \mathrm{~N} \mathrm{NaOH}$ is used to adjust the $\mathrm{pH}$ ranges from 2 to 11 . After equilibrium attainment the whole content is exposed to sunlight irradiation. The absorbance is measured at regular interval using UV -VIS spectrophotometer 119 with regular interval ranges from $200-800 \mathrm{~nm}$ to determine the degradation percentage of $\mathrm{MB}$ and $\mathrm{MO}$ onto CBMO. The reaction is duplicated and the means values are measured and reported. The percentage of degradation efficiency is calculated by the following equation

$\eta=\frac{A_{0}-A_{t}}{A_{0}}$

\section{SN Applied Sciences}


where $A_{0}$ is the initial absorbance of the dye and $A_{t}$ is the absorbance of dye after degradation [24].

\section{Results and discussion}

\subsection{Physiochemical characterization of CBMO}

The Physiochemical characteristic of CBMO is studied and summarized in the Table 1. Moisture content is measure of the action of composite. If the moisture content is high it dilutes the action of composite and it needs extra load of composite dosage to degrade dye. From the results it is clear that the moisture content of CBMO is low $(2.98 \%)$ compared to raw chitosan $(7.84 \%)$ shows the better removal ability of dyes from wastewater than raw chitosan [25]. The surface acidity and basicity of CBMO is $4.05 \mathrm{mmoles} / \mathrm{gm}$ and $3.02 \mathrm{mmoles} / \mathrm{gm}$ respectively. The surface acidity and basicity is confirmed by Boehm titration, which quantifies the presence of oxygenated acidic groups and basic groups on modified composite. The Boehm titration results revealed the presence of phenyl carboxyl groups on its surface is measured in mill equivalent/gram [26]. The degradation ability of the composite is directly proportional to lodine Number $(1384.31 \mathrm{mg} / \mathrm{g}$ ) and Yield (84.7\%). If the iodine number and yield is high the degradation ability is also high due to large surface area. The surface area of raw chitosan is $1.46 \mathrm{~m}^{2} / \mathrm{g}$; the result showed that the surface area of CBMO is rapidly increases by modification process. The surface area of CBMO is $41.9 \mathrm{~m}^{2} / \mathrm{g}$ enriches the uptake ability of dyes and heavy metals than raw chitosan [27]. The electrical neutrality of the composites is determined by zero point charge $\left(\mathrm{pH}_{z p c}\right)$. The result indicated that the $\mathrm{pH}_{z p c}$ of CBMO depend upon the raw material and activated agent. The $\mathrm{pH}_{\mathrm{zpc}}$ of $\mathrm{CBMO}$ is 7.2, if the solution $\mathrm{pH}$ is below than $\mathrm{pH}_{\mathrm{zpc}}$ (positively charged surface) enhances anionic dye

Table 1 Physiochemical characteristics of CBMO

\begin{tabular}{lc}
\hline Parameters & CBMO \\
\hline Yield (\%) & 84.7 \\
Moisture content (\%) & 2.98 \\
$\mathrm{pH}$ & 6.8 \\
Surface acidity (mmoles/g) & 4.05 \\
Surface basicity (mmoles/g) & 3.02 \\
$\mathrm{pH}_{\text {zpc }}$ & 7.2 \\
Boehm titration (m eq/gm) Basic sites & 2.25 \\
Phenolic and Carboxylic groups & 1.28 \\
Carboxyl groups & 0.52 \\
lodine number (mg/g) & 1384.31 \\
Surface area $\left(\mathrm{m}^{2} / \mathrm{g}\right)$ & 41.9 \\
\hline
\end{tabular}

degradation and if the $\mathrm{pH}$ is above than $\mathrm{pH}_{\mathrm{zpc}}$ (negatively charged surface) enhances cationic dye degradation [28].

\subsection{Surface characterization of CBMO}

The SEM image of the prepared CBMO at $1000 \times$ magnification is shown in Fig. 1. It represents the surface morphology of the prepared composite. CBMO surface has single phase primary particles and it has porous structure [29].

Qualitative confirmation of CBMO is studied by EDX technique as shown in the Fig. 2. The mass $\%$ and atomic mass $\%$ of CBMO is summarized in Table 2.

$X$-ray diffraction pattern of $C B M O$ is shown in Fig. 3. The $2 \theta$ values lies between 20 and $30^{\circ}, 45^{\circ}$ and $65^{\circ}$ indicates the composite is partially crystalline and amorphous in nature [30].

Characterization of functional groups is confirmed by FTIR spectral peaks. The sharp peak at $3254.67 \mathrm{~cm}^{-1}$ indicates the presence of free - $\mathrm{OH}$ group. The wide bond lies between 2000 and $2021 \mathrm{~cm}^{-1}$ represents the presence of overtone bands. The band at $1651.74 \mathrm{~cm}^{-1}$ show the presence of $\mathrm{N}-\mathrm{H}$ bending of primary amines, similar result was observed in the previous literature [31]. The peak

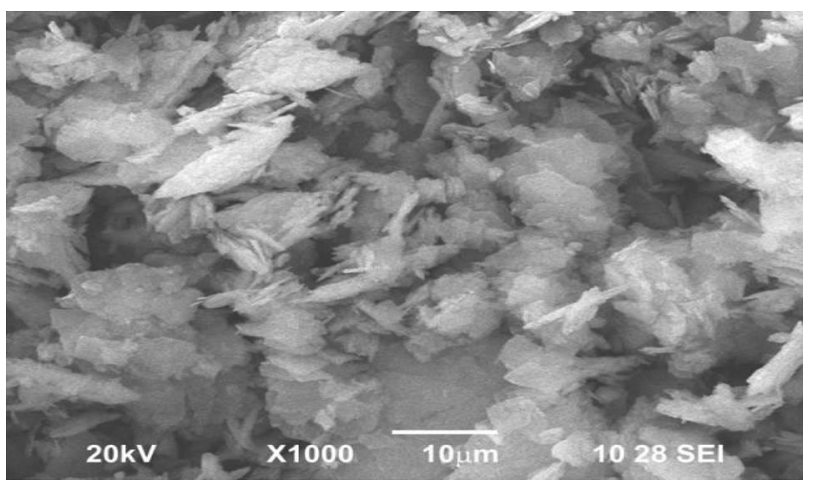

Fig. 1 SEM image of CBMO

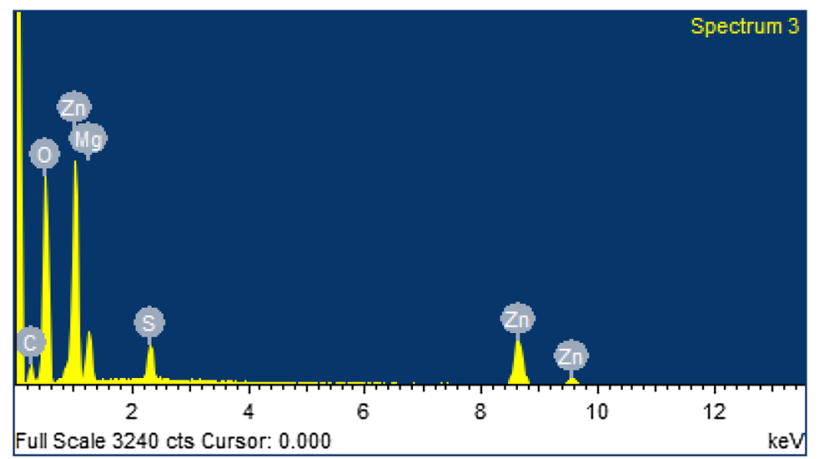

Fig. 2 EDX image of CBMO 
Table 2 EDX elemental analysis of CBMO

at $1377.47 \mathrm{~cm}^{-1}$ represents the stretching of $\mathrm{C}-\mathrm{N}$ bond between chitosan and metal oxide [32]. The band ranges from 1070.71 to $1310.31 \mathrm{~cm}^{-1}$ indicating $\mathrm{C}=\mathrm{O}$ stretching in alcohols and phenols [33] is shown in Fig. 4.

\subsection{Photocatalytic studies for the degradation of $\mathrm{MB}$ and $\mathrm{MO}$ dye onto CBMO using solar light irradiation}

\subsubsection{Effect of irradiation time}

The effect of irradiation time is the predominant factor to determine the degradation capacity of CBMO towards $\mathrm{MB}$ and $\mathrm{MO}$. It is studied by the varied irradiation time from 20 to $140 \mathrm{~min}$ at optimum dose of $0.15 \mathrm{~g}$ of CBMO. From the results of photo catalytic studies, the initial dye concentration is fixed as $10 \mathrm{mg} / \mathrm{L}$. The degradation percentage of $\mathrm{MB}$ is $67.43 \%$ and $\mathrm{MO}$ is $74.05 \%$ respectively. Degradation of the MB and MO increases with increase in irradiation time up to 120 min which attributed to higher number of active sites. After that there is no optimal change observed in the degradation efficiency since lesser number of active sites are available in the surface of CBMO [34]. The relationship between irradiation time

Fig. 3 XRD image of CBMO

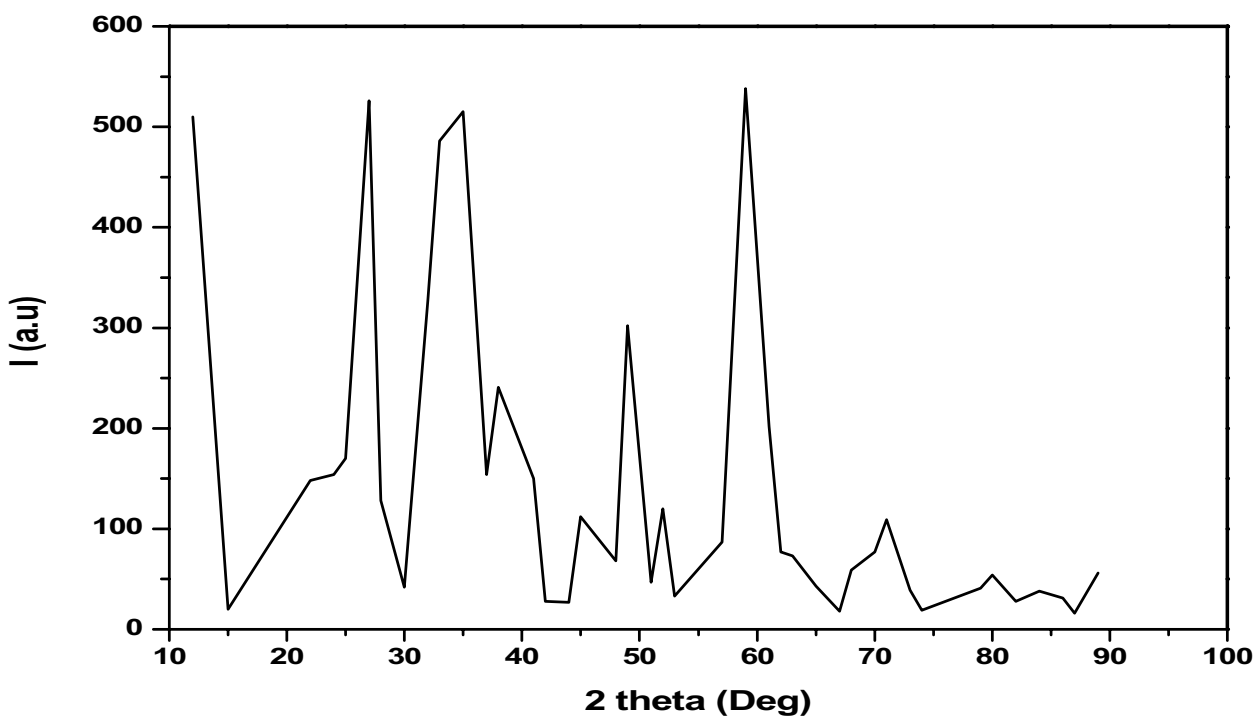

Fig. 4 FTIR image of CBMO

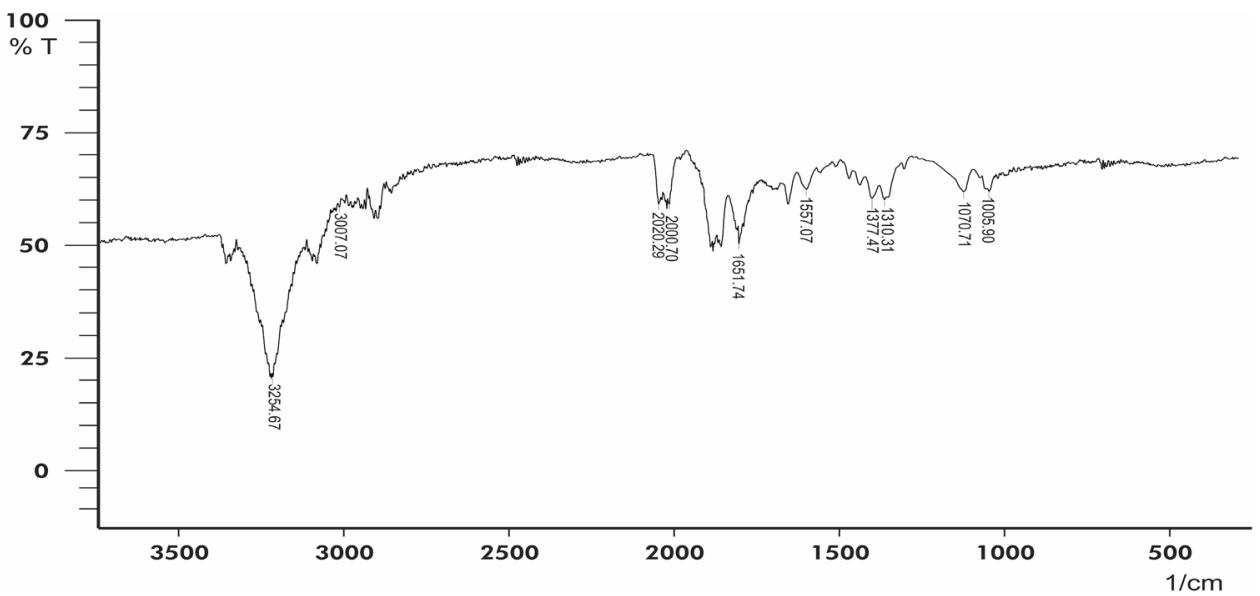




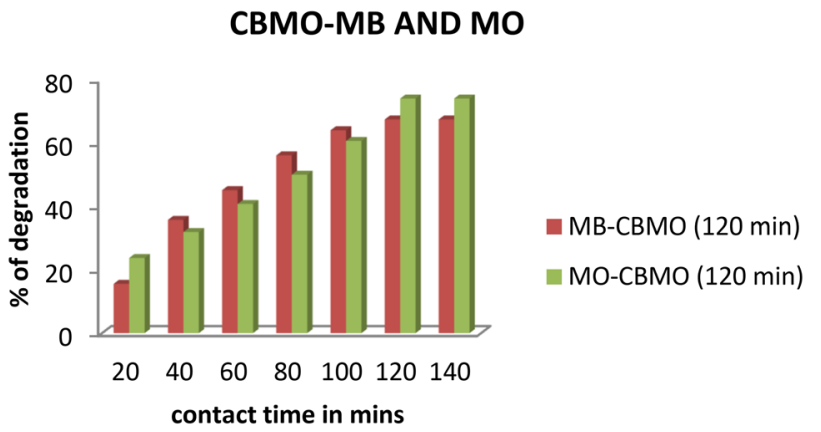

Fig. 5 Effect of irradiation time and \% of degradation (CBMO dose $=0.15 \mathrm{~g}, \mathrm{pH}=8$ for $\mathrm{MB}$ and 3 for $\mathrm{MO}$ and initial dye concentration $10 \mathrm{mg} / \mathrm{L})$

and \% of degradation is shown in Fig. 5. The results indicate that the degradation of $\mathrm{MO}$ is higher than $\mathrm{MB}$ onto $\mathrm{CBMO}$, therefore the composite favours anionic dye than cationic dye.

\subsubsection{Effect of $\mathrm{pH}$}

The degradation of $\mathrm{MB}$ and $\mathrm{MO}$ onto $\mathrm{CBMO}$ as a function of hydrogen ion concentration is investigated from $\mathrm{pH} 2$ to 11 at optimum dose of $0.15 \mathrm{~g}$ of composite and the irradiation time of $120 \mathrm{~min}$. The solution $\mathrm{pH}$ is the primary tool to find the degradation efficiency of CBMO. The relationship between $\mathrm{pH}$ and $\%$ of degradation is shown in Fig. 6. Maximum percentage of degradation is $67.43 \%$ at $\mathrm{pH} 8$ for $\mathrm{MB}$ and $74.05 \%$ at $\mathrm{pH} 3$ for $\mathrm{MO}$ respectively. If zero point charge of CBMO (7.2) is lower than the solution $\mathrm{pH}$, it enhances the methylene blue dye degradation because it possesses negative charge on its surface. Based on the observation of effect of $\mathrm{pH}$, the zero point charge of the CBMO is higher than the solution $\mathrm{pH}$ it enriches the degradation of anionic dyes

\section{CBMO-MB and MO}

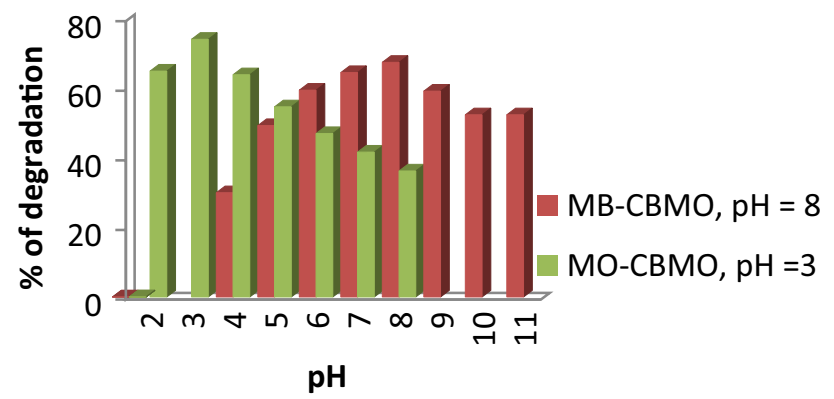

Fig. 6 Effect of $\mathrm{pH}$ and \% of degradation (CBMO dose $=0.15 \mathrm{~g}$, irradiation time $=120 \mathrm{~min}$ and initial dye concentration $10 \mathrm{mg} / \mathrm{L}$ )

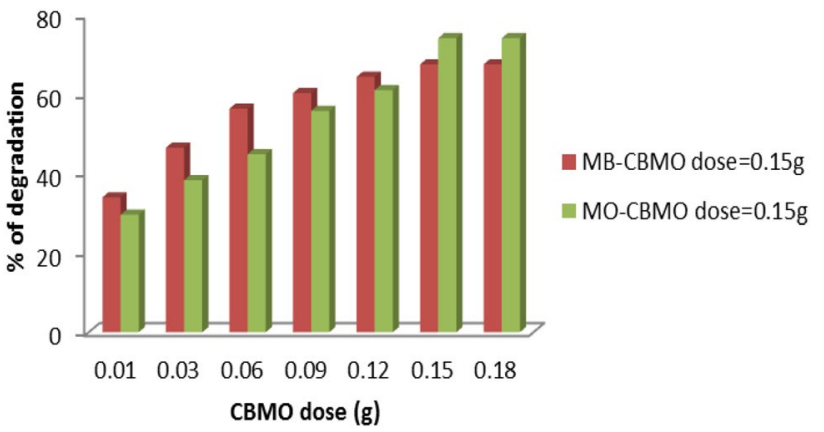

Fig. 7 Effect of CBMO dose and \% of degradation $(\mathrm{pH}=8$ for $\mathrm{MB}$ and 3 for $\mathrm{MO}$, irradiation time $=120 \mathrm{~min}$ and initial dye concentration $10 \mathrm{mg} / \mathrm{L}$ )

since the surface of the composite is positively charged [35]. Similar results are observed by several researchers using modified chitosan composites as a photo catalyst in dye removal process. From the result it may come to the conclusion that CBMO can be used as an effective photo catalyst to degrade MO than MB.

\subsubsection{Effect of CBMO dose}

The degradation capacity of $\mathrm{MB}$ and $\mathrm{MO}$ onto $\mathrm{CBMO}$ is studied by varying the amount of composite from 0.01 to $0.18 \mathrm{~g}$ at optimum conditions. The plot of CBMO dose and the $\%$ of degradation of $\mathrm{MB}$ and $\mathrm{MO}$ are shown in the Fig. 7. From the figure it is clear that the percentage of degradation increases steadily with increase in CBMO dose up to $0.15 \mathrm{~g}$ at lower concentration of dye solution. The maximum degradation of $\mathrm{MB}$ is $67.43 \%$ and $74.05 \%$ for $\mathrm{MO}$. After this there is no considerable change in the percentage of degradation in $\mathrm{MB}$ and $\mathrm{MO}$, this may be attributed that the formation of cloudy and non-transparent solution is due to the excess addition of CBMO with dye solution, this restrict the penetration of light into the dye solution [36]. Hence $0.15 \mathrm{~g}$ of the composite is fixed as optimum dose for entire study.

\subsubsection{Effect of Initial dye concentration}

Effect of initial dye concentration is analysed by varying the concentration of $\mathrm{MB}$ and $\mathrm{MO}$ concentration which ranges from $10 \mathrm{mg} / \mathrm{L}$ to $70 \mathrm{mg} / \mathrm{L}$ and the relationship between initial dye concentration and $\%$ of degradation is shown in Fig. 8. The \% of degradation of MB dye decreased from 67.43 to $22.8 \%$ and $\mathrm{MO}$ decreased from 74.05 to $21.9 \%$. When the concentration of dye increases the uptake capacity of CBMO decreases, because the formation of $\mathrm{OH}^{-}$reduced at this stage, it is the prime and foremost reason for degradation of dye [37]. 


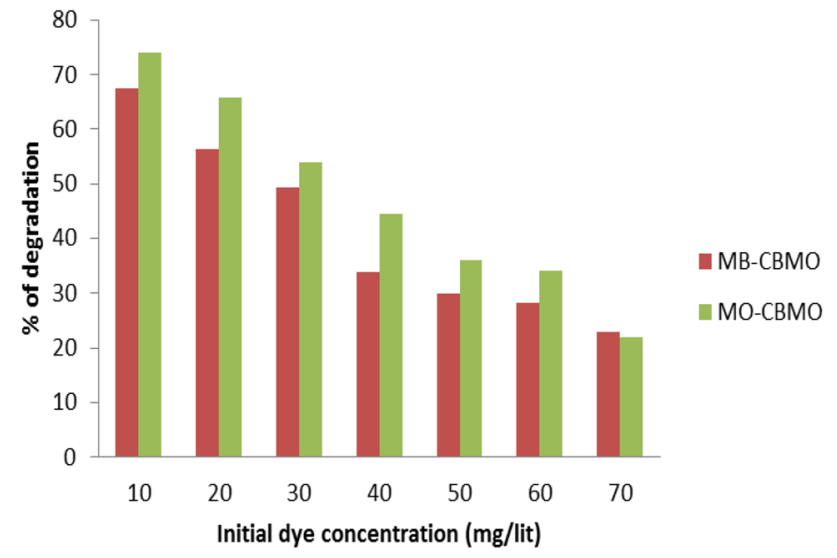

Fig. 8 Effect of Initial dye concentration on the degradation efficiency of CBMO ( $\mathrm{pH}=8$ for $\mathrm{MB}$ and 3 for $\mathrm{MO}$ CBMO dose $=0.15 \mathrm{~g}$ and irradiation time $=120 \mathrm{~min}$ )

\subsubsection{Conformation analysis for the degradation of methylene blue and methyl orange}

The degradation of MB and MO by solar light irradiation is confirmed by UV-Visible spectroscopic studies as shown in Fig. $9 a$, b. The quantity of dye degraded is determined by using UV-VIS spectrophotometer 119 at $663 \mathrm{~nm}$ for MB and $464 \mathrm{~nm}$ for MO. The decrease in absorbance indicates the increase in \% of dye degradation at regular interval time of $20 \mathrm{~min}$ at optimum conditions in the presence of solar light. The degradation of $\mathrm{MB}$ and $\mathrm{MO}$ onto $\mathrm{CBMO}$ before and after treatment is shown in Fig. 10a, b.

Many researchers have made attempt using various materials for the degradation of $\mathrm{MB}$ and $\mathrm{MO}$ are reported and summarized in the Table 3 . The result shows that the degradation efficiency of CBMO is high with the contact time of $120 \mathrm{~min}$, when compared to other studied materials using UV light and sunlight irradiation.

\subsubsection{Comparative study of synthetic and industrial wastewater using CBMO as a photo catalyst}

The degradation efficiency of CBMO is also analysed with industrial wastewater, which is collected from Mangalam, Tirupur district. The results of both synthetic and industrial wastewater onto CBMO are compared and summarized in Table 4. The results proved that the percentage degradation of CBMO towards synthetic and industrial wastewater is more or less equal indicates that the CBMO can also be used in industrial level as an effective photo catalyst. Degradation percentage is confirmed by UV- spectral studies for the industrial wastewater onto CBMO and is shown in the Fig. 11. The results of UV spectral analysis showed that there is a decrease in absorbance, indicates the $\%$ of dye degraded with respect to time onto $\mathrm{CBMO}$.
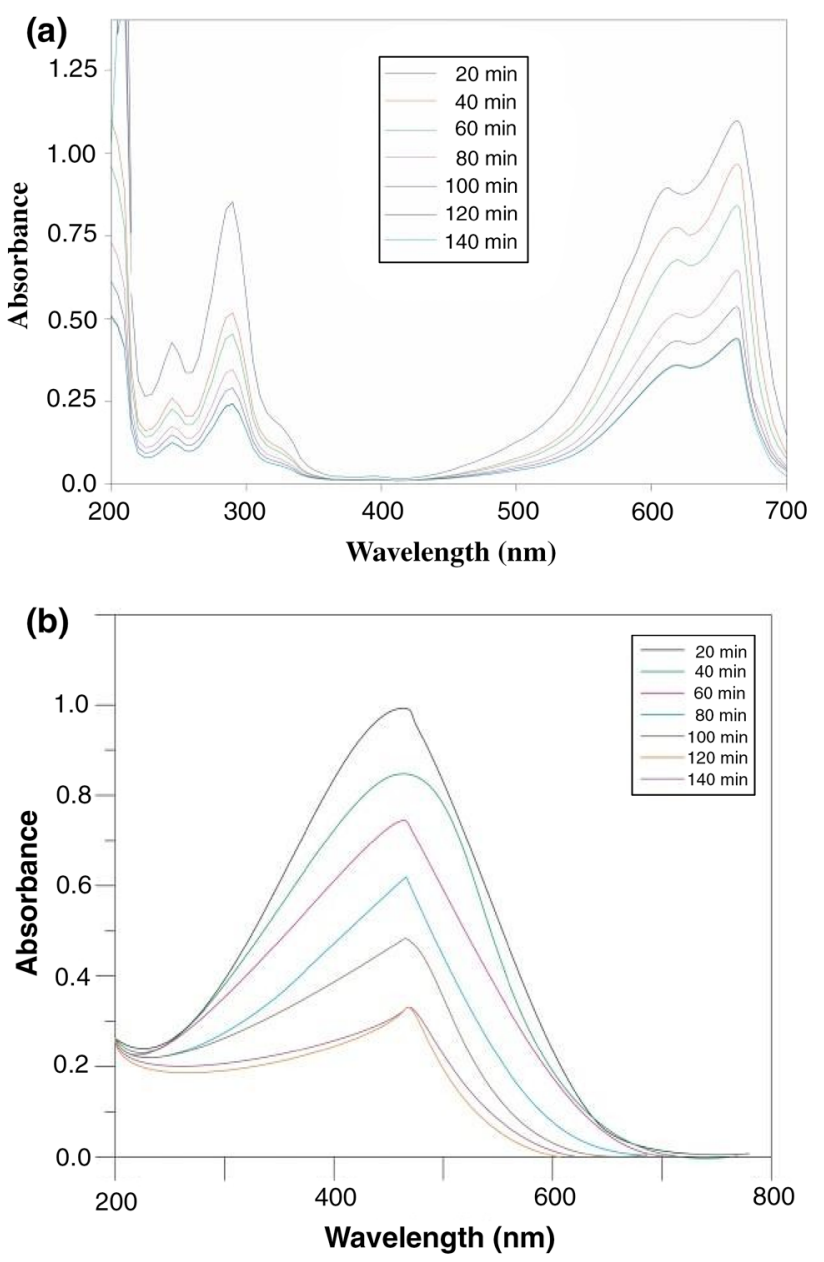

Fig. 9 UV visible sepctrum for the degradation of a $\mathrm{MB}$ onto $\mathrm{CBMO}$, b $\mathrm{MO}$ onto $\mathrm{CBMO}$

\subsection{Adsorption isotherms}

Based on the equilibrium data Freundlich and Langmuir isotherms are used to determine the maximum degradation capacity of $\mathrm{MB}$ and $\mathrm{MO}$ onto CBMO. The empirical form of Freundlich isotherm and the linear form of Langmuir equation is given below;

$\log q_{e}=\frac{1}{n} \log \left(C_{e}\right)+\log K_{f}$

$\frac{C_{e}}{q_{e}}=\frac{1}{q_{\max }} b+\frac{C_{e}}{q_{\max }}$

where $\mathrm{q}_{\mathrm{e}}$ is the $\mathrm{MB}$ and $\mathrm{MO}$ dye concentration in CBMO $(\mathrm{mg} / \mathrm{g}), 1 / \mathrm{n}$ is the heterogeneity factor, $C_{e}$ is the concentration of dye solution $(\mathrm{mg} / \mathrm{L}), \mathrm{K}_{\mathrm{f}}$ is the Freundlich constant $(\mathrm{mg} / \mathrm{g}), \mathrm{q}_{\max }$ is the maximum degradation potential $(\mathrm{mg} / \mathrm{g})$ and $\mathrm{b}$ is the Langmuir equilibrium constant 

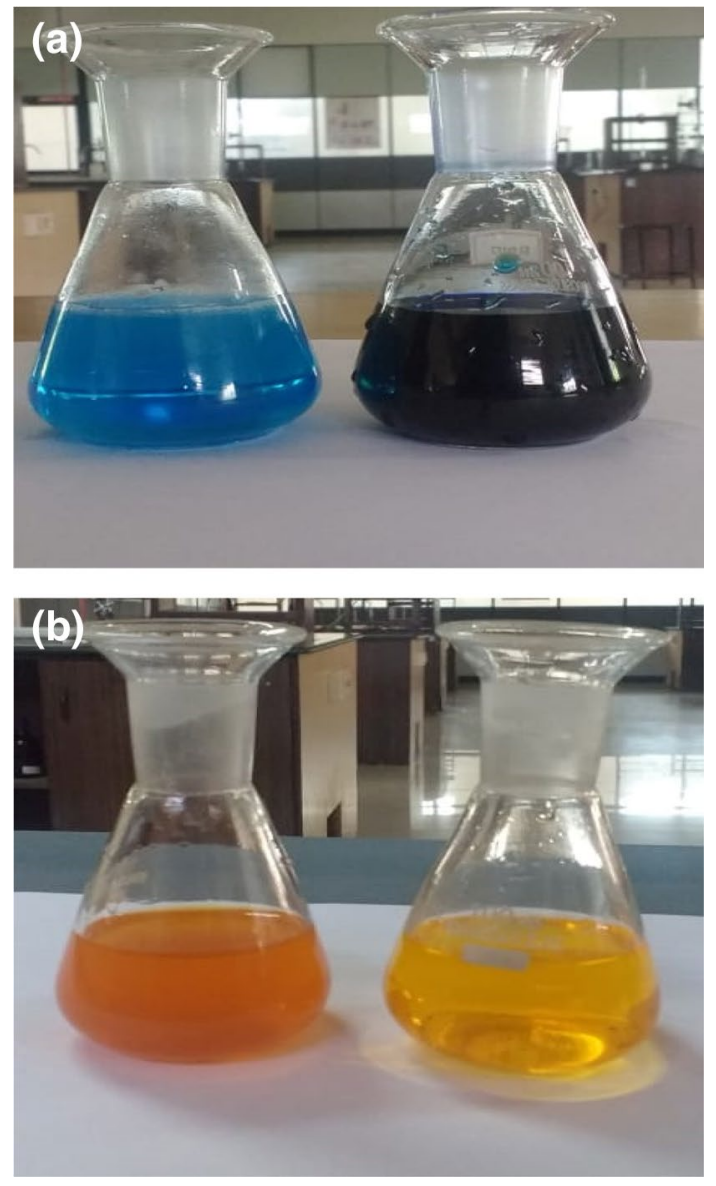

Fig. 10 a Degradation of $M B$ onto CBMO before and after treatment. $\mathbf{b}$ Degradation of MO onto CBMO before and after treatment
$[38,39]$. Based on the result the correlation regression coefficient of MB (0.9919) and MO (0.9914) onto CBMO is higher for Langmuir isotherm than Freundlich isotherm model which revealed that the formation of strong mono layer and homogeneous surface during degradation process. The maximum degradation capacity $\left(\mathrm{Q}_{m}\right)$ of $C B M O$ for $M B$ is $5.9031 \mathrm{mg} / \mathrm{g}$ and for $M O$ is $5.561 \mathrm{mg} / \mathrm{g}$ respectively. The Freundlich and Langmuir isotherm models are shown in the Figs. 12 and 13.

The results revealed that the Langmuir Isotherm model is best fit for the equilibrium data than Freundlich Isotherm model. The isotherm parameters are summarized in the Table 5.

\subsection{Adsorption kinetics}

The rate of the degradation and the mechanism of the adsorption of $\mathrm{MB}$ and $\mathrm{MO}$ can be analysed by pseudo first and second order kinetics. The linear form of pseudo first order reaction is given as $[40,41]$.

$\log \left(q_{e-} q_{t}\right)=\log q_{e}-\frac{K_{1} t}{2.303}$

$\mathrm{K}_{1}$ is the first order rate constant for the degradation of $\mathrm{MB}$ and $\mathrm{MO}$ onto CBMO is 0.0696 and $0.0712 \mathrm{~min}^{-1}$. The correlation regression coefficient for first order kinetics is 0.853 for $M B$ and 0.8031 for $M O$ degradation. $\mathrm{q}_{e}$ is the uptake of dye at moment $t$ is calculated as $16.59 \mathrm{mg} / \mathrm{g}$ and $18.21 \mathrm{mg} / \mathrm{g}$ for $\mathrm{MB}$ and $\mathrm{MO}$ onto CBMO. A graph is plotted
Table 3 Comparative study of methylene blue and methyl orange dye degradation using various materials

\begin{tabular}{|c|c|c|c|}
\hline Name of the dye & Materials used & $\begin{array}{l}\% \text { of degradation } \\
\text { and irradiation time }\end{array}$ & Light source \\
\hline \multirow[t]{6}{*}{ Methylene blue } & $\mathrm{Cu}_{2} \mathrm{O} / \mathrm{LDH}$ (layered double hydroxide) & $\begin{array}{l}51.8 \% \\
6 \mathrm{~h}\end{array}$ & Solar light irradiation \\
\hline & Chitosan Zinc Oxide hybrid composite & $\begin{array}{l}64 \% \\
3 \mathrm{~h}\end{array}$ & UV light irradiation \\
\hline & $\mathrm{BiFeO}_{3}$ & $\begin{array}{l}35 \% \\
9 \mathrm{~h}\end{array}$ & Solar light irradiation \\
\hline & $\mathrm{ZnO}$ & $\begin{array}{l}50 \% \\
4 \mathrm{~h}\end{array}$ & Solar light irradiation \\
\hline & $\mathrm{CuCl}_{2}+\mathrm{STS}$ & $\begin{array}{l}68.1 \% \\
24 \mathrm{~h}\end{array}$ & Solar light irradiation \\
\hline & $\begin{array}{l}\text { CBMO } \\
\text { (Present study) }\end{array}$ & $\begin{array}{l}67.43 \% \\
2 \mathrm{~h}\end{array}$ & Solar light irradiation \\
\hline \multirow[t]{4}{*}{ Methyl orange } & Chitosan-g-Poly (acrylamide)/ZnS & $\begin{array}{l}69 \% \\
4 \mathrm{~h}\end{array}$ & Solar light irradiation \\
\hline & Chitosan/LaFe ${ }_{0.8} \mathrm{Cu}_{0.2} \mathrm{O}_{3}$ & $\begin{array}{l}67 \% \\
8 \mathrm{~h}\end{array}$ & UV light irradiation \\
\hline & Xylan/LaFe ${ }_{0.8} \mathrm{Cu}_{0.2} \mathrm{O}_{3}$ & $\begin{array}{l}58 \% \\
8 \mathrm{~h}\end{array}$ & UV light irradiation \\
\hline & $\begin{array}{l}\text { CBMO } \\
\text { (present study) }\end{array}$ & $\begin{array}{l}74.05 \% \\
2 \mathrm{~h}\end{array}$ & Solar light irradiation \\
\hline
\end{tabular}


Fig. 12 Freundlich isotherm a for $\mathrm{MB}$ onto $\mathrm{CBMO}, \mathbf{b}$ for $\mathrm{MO}$ onto $\mathrm{CBMO}$
Table 4 Comparative analysis of synthetic and industrial wastewater onto $\mathrm{CBMO}$

\begin{tabular}{|c|c|c|c|c|}
\hline \multirow[t]{3}{*}{ Composite } & \multirow{3}{*}{$\begin{array}{l}\text { Degrada- } \\
\text { tion time }\end{array}$} & \multicolumn{3}{|c|}{$\%$ of degradation } \\
\hline & & \multicolumn{2}{|c|}{ Synthetic wastewater } & \multirow{2}{*}{$\begin{array}{l}\text { Industrial } \\
\text { wastewate }\end{array}$} \\
\hline & & $\begin{array}{l}\text { Methylene } \\
\text { blue }\end{array}$ & $\begin{array}{l}\text { Methyl } \\
\text { orange }\end{array}$ & \\
\hline CBMO & $120 \mathrm{~min}$ & 67.43 & 74.05 & 62.05 \\
\hline
\end{tabular}

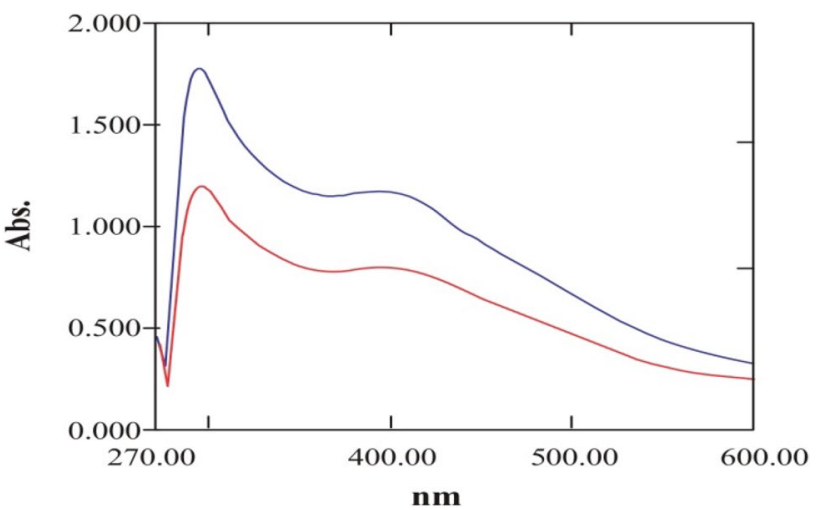

$\mathrm{K}_{2}$ is the equilibrium rate constant for the adsorption of $\mathrm{MB}$ and $\mathrm{MO}$ onto $\mathrm{CBMO}$ is 0.00072 and $0.00015 \mathrm{~g} /$ $\mathrm{mg}$ min respectively, $\mathrm{q}_{\mathrm{t}}$ is the uptake of dye at moment $t$ and the amount of dye adsorbed at equilibrium time $\mathrm{q}_{\mathrm{e}}$ is 24.03 and $39.37 \mathrm{mg} / \mathrm{g}$. The regression coefficient $\mathrm{R}^{2}$ for the adsorption of $\mathrm{MB}$ is 0.9929 and 0.9916 for $\mathrm{MO}$ indicates the equilibrium data is well fitted for pseudo second order kinetic model when compared to pseudo first order kinetic model.

The kinetic parameters for the degradation of $\mathrm{MB}$ and MO onto CBMO are summarized in the Table 6.
Fig. 11 UV-Spectra of industrial wastewater onto CBMO

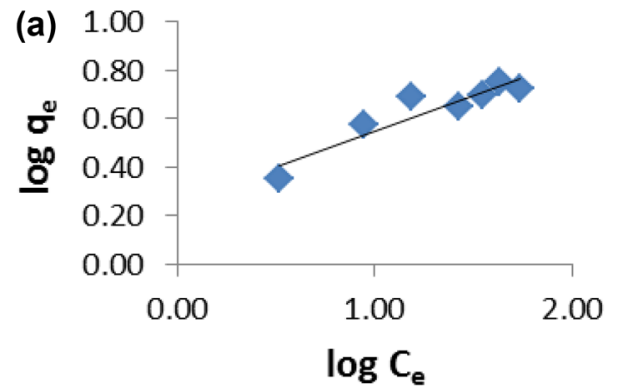

(a)

CBMO-MB

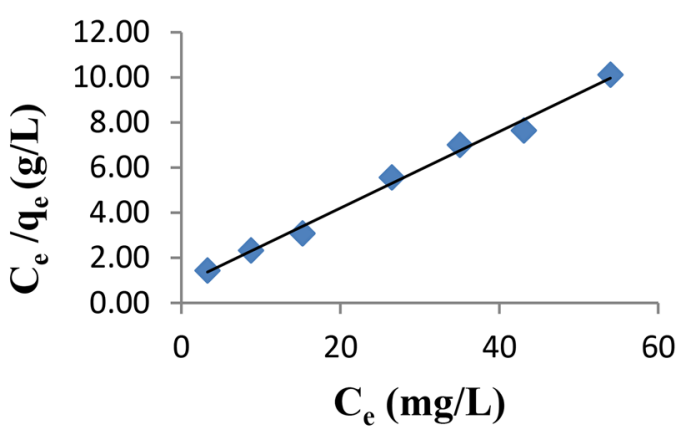

(b)

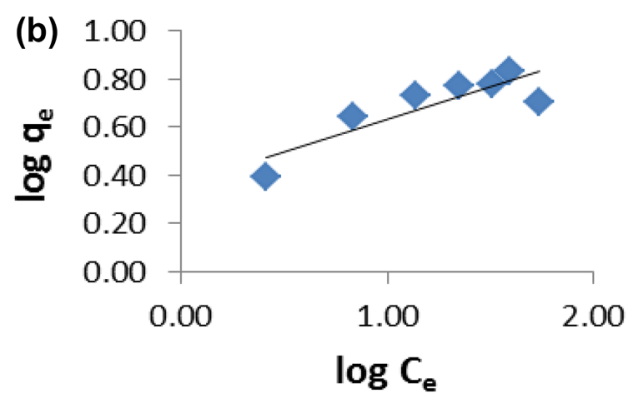

between time $t$ and $\log \left(q_{e}-q_{t}\right)$ which gives a straight line

In pseudo second order kinetics a graph is plotted between time $(t)$ versus $t / q_{t}$ as shown in the Fig. 15 . The commonly used form of pseudo second order kinetics is as follows.

$\frac{\mathrm{t}}{q_{t}}=\frac{1}{K_{2}}-\frac{t}{q_{e}}$

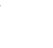

\section{.}


Table 5 Isotherm parameters for $\mathrm{MB}$ and $\mathrm{MO}$ onto $\mathrm{CBMO}$

\begin{tabular}{llll}
\hline Isotherm model & Parameters & $\mathrm{MB}$ & $\mathrm{MO}$ \\
\hline Freundlich isotherm & $1 / \mathrm{n}$ & 3.385 & 3.70 \\
& $\mathrm{~K}_{\mathrm{F}}(\mathrm{mg} / \mathrm{g})$ & 1.81 & 2.31 \\
& $\mathrm{R}^{2}$ & 0.8702 & 0.7471 \\
Langmuir isotherm & $\mathrm{Q}_{\mathrm{m}}(\mathrm{mg} / \mathrm{g})$ & 5.9031 & 5.561 \\
& $\mathrm{~b}(\mathrm{~L} / \mathrm{mg})$ & 1.151 & 2.407 \\
& $\mathrm{R}^{2}$ & 0.9919 & 0.9914 \\
\hline
\end{tabular}
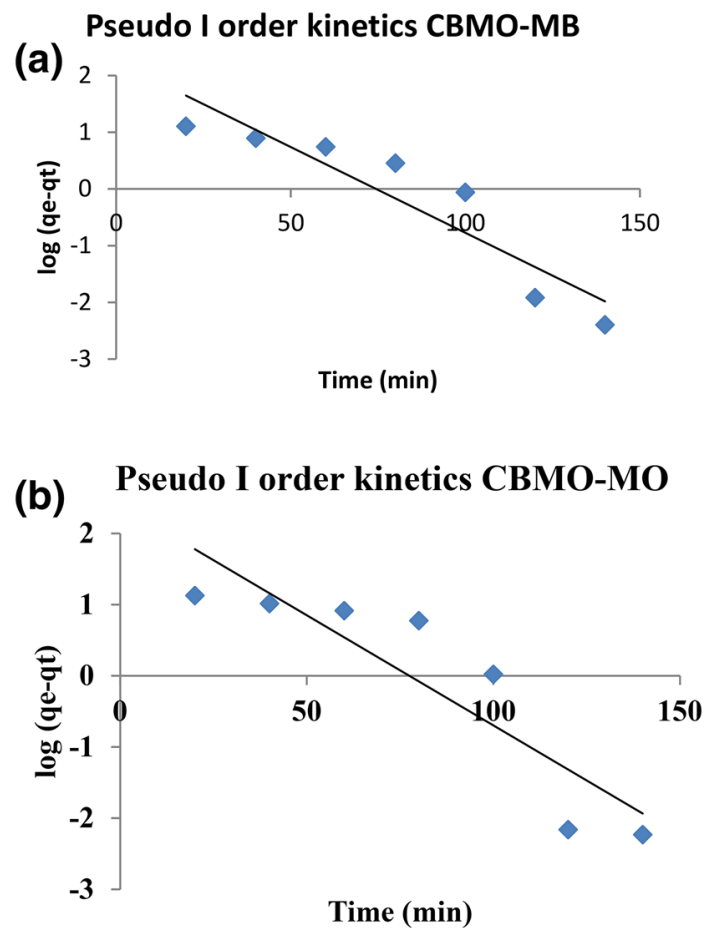

Fig. 14 Pseudo first order kinetic model for the degradation of a $\mathrm{MB}$ onto $\mathrm{CBMO}, \mathbf{b} \mathrm{MO}$ onto $\mathrm{CBMO}$

\subsection{Proposed mechanism for the degradation of methylene blue and methyl orange degradation onto CBMO}

A possible mechanism has been proposed based on the experimental results of photo catalytic degradation of $\mathrm{MB}$ and $\mathrm{MO}$ onto CBMO. The overall photo catalytic degradation is depends on the light degradation ability of the composite and separation of excited electron hole pair [42].

According to the above discussion, CBMO produce conduction band via photo catalytic method obviously increases the degradation ability of the composite and generates the separation of photo generated electronshole pair; hence a considerable photo catalytic activity
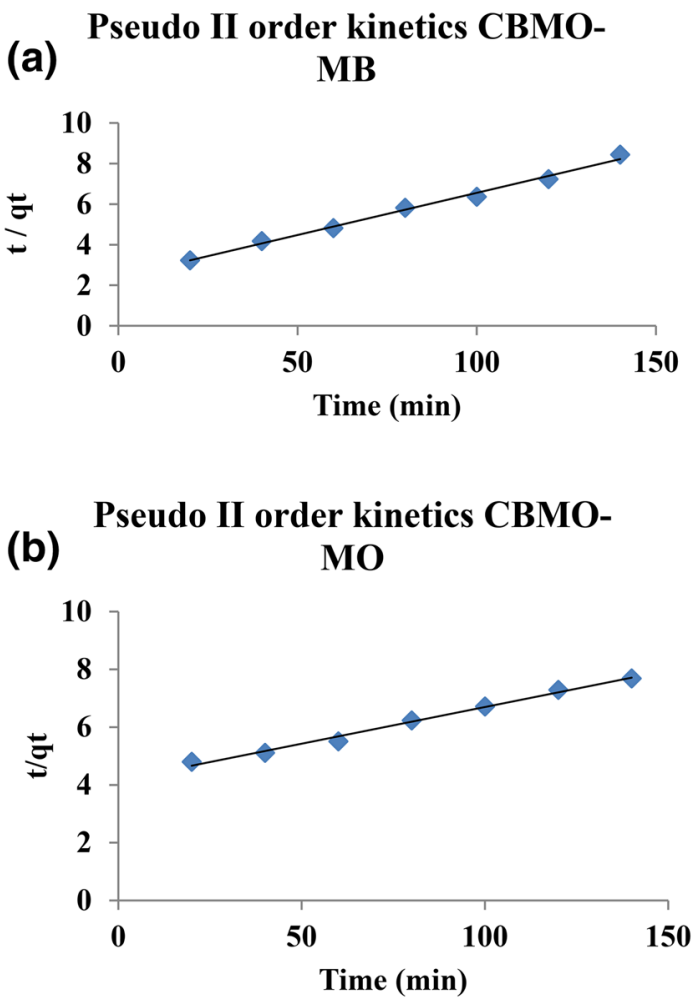

Fig. 15 Pseudo second order kinetics for the degradation of a MB onto $\mathrm{CBMO}$, b $\mathrm{MO}$ onto $\mathrm{CBMO}$

Table 6 Kinetic parameters for the degradation of $\mathrm{MB}$ and $\mathrm{MO}$ onto CBMO

\begin{tabular}{llll}
\hline Kinetic model & Parameters & $\mathrm{MB}$ & $\mathrm{MO}$ \\
\hline Pseudo first order kinetics & $\mathrm{k}_{1}\left(\mathrm{~min}^{-1}\right)$ & 0.0696 & 0.0712 \\
& $\mathrm{q}_{\mathrm{e}}(\mathrm{mg} / \mathrm{g})$ & 16.59 & 18.21 \\
& $\mathrm{R}^{2}$ & 0.853 & 0.8031 \\
Pseudo second order kinetics & $\mathrm{k}_{2}(\mathrm{~g} / \mathrm{mg} \mathrm{min})$ & 0.00072 & 0.00015 \\
& $\mathrm{q}_{\mathrm{e}}(\mathrm{mg} / \mathrm{g})$ & 24.03 & 39.37 \\
& $\mathrm{~h}$ & 0.415 & 0.24 \\
& $\mathrm{R}^{2}$ & 0.9929 & 0.9916 \\
\hline
\end{tabular}

[43] is achieved. The possible mechanism may be given as follows

$\mathrm{CBMO}+\mathrm{h} \nu \rightarrow \mathrm{CBMO}\left(\mathrm{e}_{\mathrm{CB}}^{-}+\mathrm{h}_{\mathrm{CB}}^{+}\right)$

$\mathrm{CBMO}\left(\mathrm{e}_{\mathrm{CB}}^{-}\right)+\mathrm{O}_{2} \rightarrow \mathrm{CBMO}+\mathrm{O}_{2}^{--}$(superoxide formation)

$\mathrm{O}_{2}^{--}+\mathrm{e}^{-}+2 \mathrm{H}^{+} \rightarrow 2 \mathrm{OH}^{-}$(Free radical formation)

$\mathrm{CBMO}\left(\mathrm{h}_{\mathrm{CB}}^{+}\right)+\mathrm{OH}^{-} \rightarrow \mathrm{OH}^{-}+\mathrm{CBMO}$ 


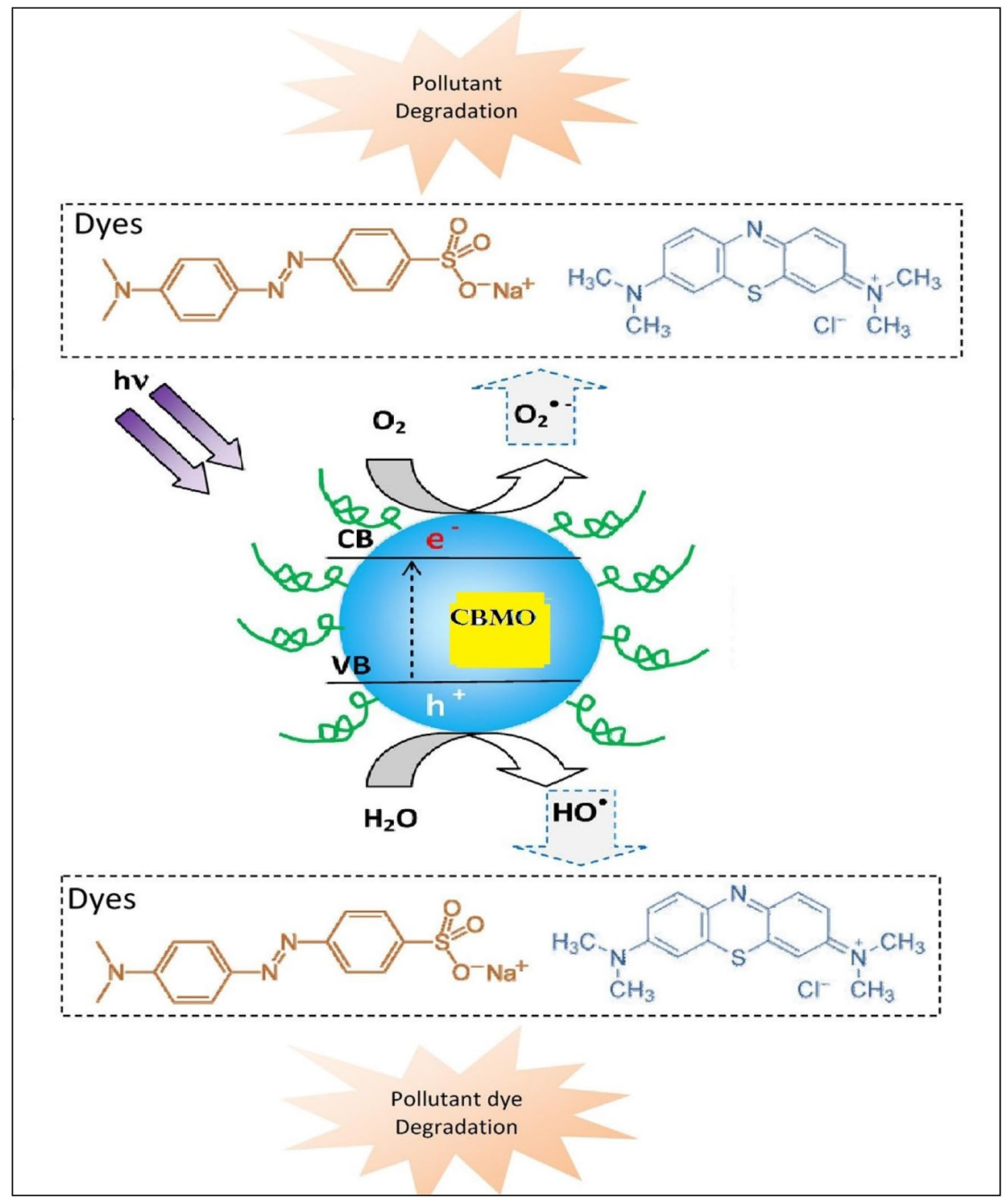

Fig. 16 Proposed mechanisms for the degradation of $\mathrm{MB}$ and $\mathrm{MO}$ onto $\mathrm{CBMO}$

$\mathrm{OH}^{`}+$ Dye $(\mathrm{MB}$ and $\mathrm{MO}) \rightarrow$ Degradation Products

$\mathrm{O}_{2}^{--}+$Dye $(\mathrm{MB}$ and $\mathrm{MO}) \rightarrow$ Degradation Products

The predicted mechanism for the degradation of $\mathrm{MB}$ and $\mathrm{MO}$ onto $\mathrm{CBMO}$ is given in the Fig. 16 , which gives the clear mechanism of the degradation process.

\section{Conclusion}

The present research paper focuses on the preparation and utilization of modified chitosan composite (CBMO) to investigate the degradation and adsorption efficiencies of $\mathrm{MB}$ and $\mathrm{MO}$ dyes by photocatalytic degradation studies using solar light as an illuminant. The physiochemical and surface characterization is studied for the prepared 
composites and is reported. By varying irradiation time, $\mathrm{pH}, \mathrm{CBMO}$ dose and initial dye concentration of $\mathrm{MB}$ and $\mathrm{MO}$ the optimum conditions are determined and fixed for entire studies. The result of synthetic wastewater is compared with industrial wastewater to determine the maximum \% of degradation efficiency of CBMO. Based on results the optimum irradiation time is $120 \mathrm{~min}, \mathrm{pH} 8$ for $\mathrm{MB}$ and $\mathrm{pH} 3$ for $\mathrm{MO}$ and the optimum dose of $\mathrm{CBMO}$ is $0.15 \mathrm{~g}$. The maximum degradation of synthetic $M B$ is $67.43 \%$ and $\mathrm{MO}$ is $74.05 \%$ at optimum conditions and for industrial wastewater the maximum degradation is $62.05 \%$ indicates the photo catalyst is effectively suitable for both synthetic and industrial wastewater. The maximum adsorption capacity of $\mathrm{MB}$ and $\mathrm{MO}$ onto $\mathrm{CBMO}$ is $5.90 \mathrm{mg} / \mathrm{g}$ and $5.56 \mathrm{mg} / \mathrm{g}$ respectively. The experimental data is well fitted for pseudo second order kinetics and Langmuir adsorption isotherm shows that the adsorption of $\mathrm{MB}$ and $\mathrm{MO}$ onto $\mathrm{CBMO}$ is composite dependent and monolayer formation occurred in homogeneous surface of the composite. Possible mechanism for the degradation $\mathrm{MB}$ and $\mathrm{MO}$ onto $\mathrm{CBMO}$ is clearly explains the path way of the degradation. Based on this study CBMO can be recommended as a catalyst for the removal of synthetic as well as industrial wastewater.

Funding This study was not funded by any company or research grants.

\section{Compliance with ethical standards}

Conflict of interest The authors declare that they have no conflict of interest.

\section{References}

1. Gusmao KA, Gurgel LV, Melo TM, Gil LF (2013) Adsorption studies of methylene blue and gentian violet on sugarcane bagasse modified with EDTA dianhydride (EDTAD) in aqueous solutions: kinetic and equilibrium aspects. J Environ Manag 118:135-143

2. Anbia M, Salehi S (2012) Removal of acid dyes from aqueous media by adsorption onto amino-functionalized nanoporous silica SBA-3. Dyes Pigments 94(1):1-9

3. Nethaji S, Sivasamy A, Thennarasu G, Saravanan S (2010) Adsorption of Malachite Green dye onto activated carbon derived from Borassus aethiopum flower biomass. J Hazard Mater 181(1-3):271-280

4. Mohammadi A, Daemi H, Barikani M (2014) Fast removal of malachite green dye using novel super paramagnetic sodium alginate-coated $\mathrm{Fe}_{3} \mathrm{O}_{4}$ nanoparticles. Int J Biol Macromol 69:447-455

5. Bhattacharya K, Sharma A (2005) Kinetics and thermodynamics of methylene blue adsorption on neem (Azadirachta Indica) leaf powder. Dyes Pigments 65(1):51-59

6. Jamshidi M, Ghaedi M, Dashtian K, Hajati S, Bazrafshan AA (2016) Sonochemical assisted hydrothermal synthesis of $\mathrm{ZnO}$
Cr nanoparticles loaded activated carbon for simultaneous ultrasound-assisted adsorption of ternary toxic organic dye: derivative spectrophotometric, optimization, kinetic and isotherm study. Ultrason Sonochem 32:119-131

7. Azad FN, Ghaedi M, Dashtian K, Hajati S, Pezeshkpour V (2016) Ultrasonically assisted hydrothermal synthesis of activated carbon-HKUST-1-MOF hybrid for efficient simultaneous ultrasoundassisted removal of ternary organic dyes and antibacterial investigation:Taguchi optimization. Ultrason Sonochem 31:383-393

8. Chiou MS, Chuang GS (2006) Competitive adsorption of dye metanil yellow and RB15 in acid solutions on chemically crosslinked chitosan beads. Chemosphere 62(2006):731-740

9. Sakthivel S, Neppolian B, Shankar MV, Arabindoo B, Palanichamy M, Murugesan V (2003) Solar photocatalytic degradation of azo dye: comparison of photo catalytic efficiency of $\mathrm{ZnO}$ and $\mathrm{TiO}_{2}$. Sol Energy Mater Sol Cells 77(1):65-82

10. Zhou $Y$, Wenjihao $H$, Jingang Yu, Jiao $F$ (2015) Effective photocatalytic degradation of methylene blue by $\mathrm{Cu}_{2} \mathrm{O} / \mathrm{MgAl}$ layered double hydroxides. React Kinet Mech Catal 115:581-596

11. Haldorai Y, Shim J-J (2013) Chitosan-Zinc oxide hybrid composite for enhanced dye degradation and antibacterial activity. Compos Interface 20(5):365-377

12. Di L, Yanga H, Xian T, Chen X (2018) Facile synthesis and enhanced visible-light photocatalytic activity of novel $\mathrm{p}-\mathrm{Ag}_{3} \mathrm{PO}_{4} / \mathrm{n}-\mathrm{BiFeO}_{3}$ heterojunction composites for dye degradation. Nanoscale Res Lett 21(5):1-13

13. Sun J-H, Dong S-Y, Feng J-L, Yin X-J, Zhao X-C (2011) Enhanced sunlight photocatalytic performance of Sn-doped $\mathrm{ZnO}$ for Methylene Blue degradation. J Mol Catal A Chem 335:145-150

14. Pathania D, Gupta D, Al-Muhtaseb AH, Sharma G, Kumar A Naushad M, Ahamad T, Alshehri SM (2016) Photocatalytic degradation of highly toxic dyes using chitosan-g-poly (acrylamide)/ZnS in presence of solar irradiation. J Photochem Photobiol A Chem 329:61-68

15. Deng A, Chen J, Li H, Ren J, Sun R, Zhao L (2014) Photo-degradation of methyl orange by polysaccharides/ $/ \mathrm{LaFe}_{0.8} \mathrm{Cu}_{0.2} \mathrm{O}_{3}$ composite films. Biol Res 9(2):2717-2726

16. Jiao T, Zhao H, Zhou J, Zhang Q, Luo X, Jie H, Peng Q, Yan $X$ (2015) Self-assembly reduced graphene oxide nanosheet hydrogel fabrication by anchorage of chitosan/silver and its potential efficient application toward dye degradation for wastewater treatments. ACS Sustain Chem Eng 3:3130-3139

17. Kyzas GZ, Bikiaris DN (2015) Recent modifications of chitosan for adsorption applications: a critical and systematic review. Mar Drugs 13(1):312-337

18. Ewecharoena A, Thiravetyan P, Wendel E, Berlagnolli H (2009) Nickel adsorption by sodium polyacrylate-grafted activated carbon. J Hazard Mater 171:335-339

19. Huang C-C, Lo S-L, Lien H-L (2015) Vitamin B12-mediated hydrodechlorination of dichloromethane by bimetallic $\mathrm{Cu} / \mathrm{Al}$ particles. Chem Eng J 273:413-420

20. Wang Z, Huang W, Peng P, Fennell DE (2015) Rapid dechlorination of 1,2,3,4-TCDD by Ag/Fe bimetallic particles. Chem Eng J 273:465-471

21. Wen Z, Zhang Y, Dai C, Chen B, Guo S, Hong Yu, Deli W (2014) Synthesis of ordered mesoporous iron manganese bimetal oxides for arsenic removal from aqueous solutions. Microporous Mesoporous Mater 200:235-244

22. O'Carroll D, Sleep B, Krol M, Boparai H, Kocur C (2013) Nanoscale zero valent iron and bimetallic particles for contaminated site remediation. Adv Water Resour 51:104-122

23. Shalaby T, Fikrt NM, Mohamed MM, El Kady MF (2014) Preparation and characterization of iron oxide nanoparticles coated with chitosan for removal of $\mathrm{Cd}(\mathrm{II})$ and $\mathrm{Cr}(\mathrm{VI})$ from aqueous solution. Water Sci Technol 70(6):1004-1010 
24. Madhusudhana N, Yogendra K, Mahadevan KM (2012) Photo catalytic degradation of violet GL2B azo dye by using calcium aluminate nanoparticle in presence of solar light. Res $\mathrm{J}$ Chem Sci 2(5):72-77

25. Al-Manhel AJ, Al-Hilphy ARS, Niamah AK, Saudi J (2018) Extraction of chitosan, characterisation and its use for water purification. J Saudi Soc Agric Sci 17:186-190

26. Makeswari M, Santhi T (2013) Tannin gel derived from leaves of Ricinus Communis as an adsorbent for the removal of $\mathrm{Cu}$ (II) and $\mathrm{Ni}(\mathrm{II})$ ions from aqueous solution. Int J Mod Eng Res 3(5):3255-3266

27. Muniyappan A, Gandhi R, Viswanathan N, Meenakshi S (2010) Preparation and application of alumina/chitosan biocomposite. Int J Biol Macromol 47:146-154

28. Furlan FR, de Melo de silva LG, Morgado AF, do Souza AAU, de Souza SMAGU (2010) Removal of reactive dyes from aqueous solutions using combined coagulation/flocculation and adsorption on activated carbon. Resour Conserv Recycl 54:283-290

29. Houache O, Al-Maamari R, Al-Rashidi B, Jibril B (2008) Study of date palm stem as raw material in the preparation of activated carbon. J Eng Res 5(2008):47-54

30. Zhang T, Zhang B, Li L, Zhao N, Xiao F (2015) Zn-Mg mixed oxide as high efficiency catalyst for the synthesis of propylene carbonate by urea alcoholysis. Catal Commun 66:38-41

31. Arafat A, Samad SA, Huq D, Moniruzzaman M, Masum S (2015) Textile dye removal from wastewater effluents using ChitosanZnO Nanocomposite. J Text Sci Eng 5(3):1-4

32. Santos JE, Dockal ER, Cavalheiro ETG (2005) Thermal behavior of Schiff bases from chitosan. J Therm Anal Cal 79:243-248

33. Karthick R, Meenakshi S (2014) Removal of Hexavalent chromium ions using poly aniline/silicagel composite. Synth Mater 198:181-187
34. Khorramfar S, Mahmoodi NM, Arami M, Gharanjig K (2010) Equilibrium and kinetic studies of the cationic dye removal capability of a novel biosorbent Tamarindus indica from textile wastewater. Color Technol 126(5):261-268

35. Stafiej A, Pyrzynska K (2007) Adsorption of heavy metal ions with carbon nanotubes. Sep Purif Technol 58:49-52

36. Niu P (2013) Photocatalytic degradation methyl orange in aqueous $\mathrm{TiO}_{2}$ suspensions. Asian J Chem 25(2):1103-1106

37. Solomon RV, Lydia IS, Merlin JP, Venuvanalingam P (2012) Enhanced photocatalytic degradation of azo dyes using nano $\mathrm{Fe}_{3} \mathrm{O}_{4}$. J Iran Chem Soc 1(2):1-3. https://doi.org/10.1007/s1373 8-011-0033-8

38. Freundlich $\mathrm{H}$ (1906) uber die Adsorption in Losungen (adsorption in solution). Z Phys Chem 57:384-470

39. Langmuir I (1918) The adsorption of gases on plane surfaces of glass, mica and platinum. J Am Chem Soc 40(9):1361-1403

40. Ho YS, Mckay G, Ho YS, Mckay G (1998) Sorption of dye from aqueous solution by peat. Chem Eng J 70:115-124

41. Ho YS, Mckay G (1998) Kinetic models for the sorption of dye from aqueous solution by wood. J Environ Sci Health Part B Process Saf Environ Prot 76:184-185

42. Rauf MA, Meetani MA, Hisaindee S (2011) An overview on the photocatalytic degradation of azo dyes in the presence of $\mathrm{TiO}_{2}$ doped with selective transition metals. Desalination 276:13-27

43. Huang $H$, Shuchen $T$, Zeng $C$, Zhang $T$, Reshak AH, Zhang $Y$ (2017) Macroscopic polarization enhancement promoting photo- and piezoelectric-induced charge separation and molecular oxygen activation. Angew Chem Int Ed 56:11860-11864

Publisher's Note Springer Nature remains neutral with regard to jurisdictional claims in published maps and institutional affiliations. 